\title{
Editoriali
}

\section{The US National Comorbidity Survey: overview and future directions}

\author{
RONALD C. KESSLER, JAMES C. ANTHONY, DANIEL G. BLAZER, EVELYN BROMET, \\ WILLIAM W. EATON, KENNETH KENDLER, MARVIN SWARTZ, \\ HANS-ULRICH WITTCHEN, SHANYANG ZHAO
}

\section{INTRODUCTION}

This report presents an overview of the results of the US National Comorbidity Survey (NCS) (Kessler et al., 1994) and future directions based on these results. The NCS is a survey that was mandated by the US Congress to study the comorbidity of substance use disorders and nonsubstance psychiatric disorders in the general population of the US. It is the first survey to administer a structured psychiatric interview for DSM-III-R disorders to a representative national sample in the US. The need for such a survey was noted nearly two decades ago in the report of the President's Commission on Mental Health and Illness (1978). It was impossible to undertake such a survey at that time, though, due to the absence of a structured research diagnostic interview capa-. ble of generating reliable psychiatric diagnoses in general population samples. Recognizing this need, the National Institute of Mental Health funded the development of the Diagnostic Interview Schedule (DIS) (Robins et al., 1981), a research diagnostic interview that can be administered by trained interviewers who are not clinicians. The DIS was first used in the Epidemiologic Catchment Area (ECA) Study, a landmark study that interviewed over 20,000 respondents in a series of five community epidemiologic surveys of the US. The ECA has been the main sour-

Indirizzo per la corrispondenza: Professor R.C. Kessler, Department of Health Care Policy, Harvard Medical School, Boston, Massachusetts 02115 (USA).

Fax + 1-(617)-432.3588.

E-mail: kessler @hcp.med.harvard.edu ce of data in the US on the prevalence of psychiatric disorders and utilization of services for these disorders for the past decade (Robins et al., 1991; Bourdon et al., 1992; Regier et al., 1993).

The NCS was designed to take the next step beyond the ECA. Three main advances are noteworthy. First, the NCS diagnoses are based on DSM-IIIR (American Psychiatric Association, 1987) rather than DSM-III (American Psychiatric Association, 1993) criteria. Questions are also included in the interview which allow comparisons with International Classification of Diseases (ICD-10) Diagnostic Criteria for Research (World Health Organization, 1991). Second, while the ECA was designed primarily as a prevalence and incidence study, the NCS was designed to be a risk factor study as well. As a result, the NCS interview contains a much more comprehensive risk factor battery than the ECA, including family history Research Diagnostic Criteria (Endicott \& Spitzer, 1978) assessments of parental psychopathology, questions about childhood family adversity, measures of social networks and support, and information about stressful life events and difficulties. Third, while the goals of the ECA to include institutional respondents and clinical reappraisals made it necessary to carry out the ECA in a small number of local samples, our different goals made it possible to carry out the NCS in a national sample. As a result, we are able to study regional variations in specific psychiatric disorders and urban-rural differences in unmet need for services as well as to provide the first nationally representative data which can be used in the current debate about health care policy in the United States. 


\section{METHODS}

\section{Sample}

The NCS is based on a stratified, multi-stage area probability sample of persons aged $15-54$ in the noninstitutionalized civilian population in the 48 coterminous States. The inclusion of respondents as young as 15 , compared to the 18 year old lower age limit found in most general population surveys, was based on an interest in minimizing recall bias of early-onset disorders. The exclusion of respondents older than 54 was based on evidence from the ECA Study that active comorbidity between substance use disorders and nonsubstance psychiatric disorders is much lower among persons older than 54 than among those 54 and younger. The NCS also includes a supplemental sample of students living in campus group housing. The survey was administered by the staff of the Survey Research Center (SRC) at the University of Michigan between September 14, 1990 and February 6, 1992. The response rate was $82.6 \%$. Cooperation in listed households did not differ markedly by age or sex, the only two listing variables available for all selected respondents. A total of 8098 respondents participated in the survey. Based on previous evidence that survey nonrespondents have higher rates of psychiatric disorder than respondents (Alluglander, 1989; Eaton et al., 1992), a supplemental nonresponse survey was carried out in parallel with the main survey. In this supplemental survey, a random sample of initial nonrespondents was offered a financial incentive to complete a short-form of the diagnostic interview. Elevated rates of both lifetime and current psychiatric disorders were found among these initial nonrespondents. A nonresponse adjustment weight was constructed for the main survey data to compensate for this systematic nonresponse. A second weight was used to adjust for variation in probabilities of selection both within and between households. A third weight was used to adjust the data to approximate the national population distributions of the cross-classification of age, sex, race/ethnicity, marital status, education, living arrangements, region, and urbanicity as defined by the 1989 US National Health Interview Survey (US Department of Health and Human Services, 1992).

\section{Diagnostic Assessment}

The psychiatric diagnoses reported below are ba- sed on the DSM-III-R (American Psychiatric Association, 1987). The diagnostic interview used to generate these diagnoses is a modified version of the Composite International Diagnostic Interview (CIDI) (World Health Organization, 1990), a state-of-theart structured diagnostic interview based on the DIS and designed to be used by trained interviewers who are not clinicians (Robins et al., 1988). We deleted diagnoses known to have low prevalence in population-based surveys such as somatization disorder. We also deleted the Folstein-McHugh MiniMental State Examination, which is included in the full CIDI, based on pilot test results showing that respondents in the 15-54 year age range only rarely have high error scores and that those with high error scores in this age range disproportionately come from the foreign born and the poorly educated rather than the cognitively impaired. Our modifications of the remaining sections of the CIDI included adding commitment and motivation probes for recall of lifetime episodes, and including clarifying probes for CIDI questions found in pilot work to be unclear or confusing to respondents.

The DSM-III-R diagnoses included in the core NCS include major depression, mania, dysthymia, panic disorder, agoraphobia without panic, social phobia, simple phobia, generalized anxiety disorder, alcohol abuse, alcohol dependence, drug abuse, drug dependence, and antisocial personality disorder. Additional diagnoses included in a probability subsample of the NCS are nonaffective psychosis and post-traumatic stress disorder. Nonaffective psychosis (NAP) is a summary category made up of schizophrenia, schizophreniform disorder, schizoaffective disorder, delusional disorder, and atypical psychosis. We also constructed a summary category for 12-month «severe» disorder, defined as either (i) 12-month mania or NAP, (ii) lifetime mania or NAP with 12-month treatment or role impairment, (iii) or 12-month depression or panic disorder with severe impairment (hospitalization or use of antipsychotic medication).

World Health Organization field trials of the CIDI have documented good inter-rater reliability, test-retest reliability, and validity of almost all diagnoses (Wittchen, 1994). The exception is acute psychotic disorder, which has been shown to be diagnosed with low reliability and validity in structured interviews like the CIDI (Anthony et al., 1985, Helzer et al., 1985). Based on this evidence, the NCS included clinical reinterviews with respondents who reported any evidence of schizophrenia or other nonaffective psy- 


\section{R.C. Kessler et al.}

choses. These reinterviews were administered by experienced clinicians using an adapted version of the Structured Clinical Interview for DSM-III-R Diagnosis (SCID) (Spitzer et al., 1992), an instrument with demonstrated reliability in the diagnosis of schizophrenia (SCID) (Williams et al., 1992). The NCS diagnoses of NAP are based on these clinical reinterviews rather than on the UM-CIDI interviews.

\section{Interviewers and interviewer training}

As noted above, the NCS was carried out by the field staff of the SRC at the University of Michigan. The 158 interviewers who participated in the NCS had an average of five years prior interviewing experience with SRC. In addition, the NCS interviewers went through a seven-day study-specific training program in the use of the UM-CIDI. Fieldwork was closely monitored throughout the entire data collection period. Three field quality control procedures are worth noting. First, completed interviews were edited by one of 18 regional supervisors before they were returned to the national field office. This allowed rapid detection of missing data and unclear responses. Incomplete interviews were returned to the interviewer, who recontacted the respondent to obtain the missing information. Second, a random sample of respondents was recontacted by the field supervisors to verify the accuracy of interviewer performance. Third, the field edits were checked at the national field office as soon as interviews were received. This provided a second check on interviewer performance as well as a check on the accuracy of the supervisor's editing. Supervisors were contacted whenever errors were found and the interview was sent back to the field for resolution.

\section{Analysis procedures}

As a result of the complex sample design and weighting, special software was required to estimate standard errors. Standard errors of proportions were estimated using the Taylor series linearization method (Woodruff \& Causey, 1976). The PSRATIO program in the OSIRIS software package (University of Michigan, 1981) was used to make these calculations. Standard errors of odds-ratios were estimated using the method of Balanced Repeated Replication (BRR) in 44 design-based balanced subsamples (Koch \& Leneshow, 1972). The LOGISTIC pro- gram in the SAS software package (SAS Institute, 1988) was used to make these calculations.

\section{RESULTS}

\section{Lifetime and recent prevalences of NCS/DSM-III-R disorders}

The results in table I show NCS/DSM-III-R lifetime (LT) and 12-month prevalence estimates for the disorders assessed in the core NCS interview. These estimates are presented without exclusions for DSM-III-R hierarchy rules. Standard errors are reported in parentheses. The most common psychiatric disorders assessed in the NCS are major depression (17.1\% LT, 10.3\% 12-month) and alcohol dependence (14.1\% LT and 7.2\% 12-month). The next most common disorders are social and simple phobias $(13.3 \%$ and $11.3 \%$ LT, respectively; $7.9 \%$ and $8.8 \% 12$-month, respectively). As a group, addictive disorders and anxiety disorders are somewhat more prevalent than affective disorders. Approximately one in every four respondents reported a lifetime history of at least one addictive disorder and a similar number reported a lifetime history of at least one anxiety disorder. Approximately one in every five respondents reported a lifetime history of at least one affective disorder. Anxiety disorders, as a group, are considerably more likely to occur in the 12 months prior to interview $(19.3 \%)$ than either addictive disorders $(11.3 \%)$ or affective disorders $(11.3 \%)$, suggesting that anxiety disorders are more chronic than either addictive disorders or affective disorders. The prevalences of other NCS disorders are much lower. Antisocial personality disorder, which was only assessed on a lifetime basis, was reported by $2.8 \%$ of respondents, while schizophrenia and other nonaffective psychoses were found among $0.5 \%$ of respondents. It is important to note that the diagnosis of NAP was based on clinical reinterviews using the SCID rather than on the lay CIDI interviews. As documented elsewhere (Kendler et $a l$., in press), the prevalence estimates for nonaffective psychoses based on the CIDI were considerably higher but were found to have low validity when judged in comparison to the clinical reappraisals.

As shown in the last row of table I, $49.7 \%$ of the sample reported a lifetime history of at least one NCS/DSM-III-R disorder and $30.9 \%$ had one or 
Table I. - Lifetime and 12-month prevalences of NCSI/DSM-III-R disorders.

\begin{tabular}{|c|c|c|c|c|c|c|c|c|c|c|c|c|}
\hline \multirow[b]{3}{*}{ Disorders } & \multicolumn{4}{|c|}{ Male } & \multicolumn{4}{|c|}{ Female } & \multicolumn{4}{|c|}{ Total } \\
\hline & \multicolumn{2}{|c|}{ Lifetime } & \multicolumn{2}{|c|}{ 12-Month } & \multicolumn{2}{|c|}{ Lifetime } & \multicolumn{2}{|c|}{ 12-Month } & \multicolumn{2}{|c|}{ Lifetime } & \multicolumn{2}{|c|}{ 12-Month } \\
\hline & $\%$ & $\left(\mathbf{s e}^{*}\right)$ & $\%$ & $\left(\mathrm{se}^{*}\right)$ & $\%$ & $\left(\mathbf{s e}^{\star}\right)$ & $\%$ & $\left(\mathrm{se}^{*}\right)$ & $\%$ & $\left(\mathrm{se}^{*}\right)$ & $\%$ & $\left(s e^{\star}\right)$ \\
\hline \multicolumn{13}{|l|}{ I. Mood Disorders } \\
\hline Major Depressive Episode & 12.7 & $(0.9)$ & 7.7 & $(0.8)$ & 21.3 & $(0.9)$ & 12.9 & $(0.8)$ & 17.1 & $(0.7)$ & 10.3 & $(0.6)$ \\
\hline Manic Episode & 1.6 & $(0.3)$ & 1.4 & $(0.3)$ & 1.7 & $(0.3)$ & 1.3 & $(0.3)$ & 1.6 & $(0.3)$ & 1.3 & $(0.2)$ \\
\hline Dysthymia & 4.8 & $(0.4)$ & 2.1 & $(0.3)$ & 8.0 & $(0.6)$ & 3.0 & $(0.4)$ & 6.4 & $(0.4)$ & 2.5 & $(0.2)$ \\
\hline Any Mood Disorder & 14.7 & $(0.8)$ & 8.5 & $(0.8)$ & 23.9 & $(0.9)$ & 14.1 & $(0.9)$ & 19.3 & $(0.7)$ & 11.3 & $(0.7)$ \\
\hline \multicolumn{13}{|l|}{ II. Anxiety Disorders } \\
\hline Panic Disorder & 2.0 & $(0.3)$ & 1.3 & $(0.3)$ & 5.0 & $(1.4)$ & 3.2 & $(0.4)$ & 3.5 & $(0.3)$ & 2.3 & $(0.3)$ \\
\hline Agoraphobia & 3.5 & $(0.4)$ & 1.7 & $(0.3)$ & 7.0 & $(0.6)$ & 3.8 & $(0.4)$ & 5.3 & $(0.4)$ & 2.8 & $(0.3)$ \\
\hline Social Phobia & 11.1 & $(0.8)$ & 6.6 & $(0.4)$ & 15.5 & $(1.0)$ & 9.1 & $(0.7)$ & 13.3 & $(0.7)$ & 7.9 & $(0.4)$ \\
\hline Simple Phobia & 6.7 & $(0.5)$ & 4.4 & $(0.5)$ & 15.7 & $(1.1)$ & 13.2 & $(0.9)$ & 11.3 & $(0.6)$ & 8.8 & $(0.5)$ \\
\hline Generalized Anxiety Disease & 3.6 & $(0.5)$ & 2.0 & $(0.3)$ & 6.6 & $(0.5)$ & 4.3 & $(0.4)$ & 5.1 & $(0.3)$ & 3.1 & $(0.3)$ \\
\hline Posttraumatic Stress Disorder & 4.8 & $(0.6)$ & 2.3 & $(0.3)$ & 10.1 & $(0.8)$ & 5.4 & $(0.7)$ & 7.6 & $(0.5)$ & 3.9 & $(0.4)$ \\
\hline Any Anxiety Disorder & 22.6 & (1.2) & 13.4 & $(0.7)$ & 34.3 & $(1.8)$ & 24.7 & (1.5) & 28.7 & $(0.9)$ & 19.3 & $(0.8)$ \\
\hline \multicolumn{13}{|l|}{ III. Addictive Disorders } \\
\hline Alcohol Abuse & 12.5 & $(0.8)$ & 3.4 & $(0.4)$ & 6.4 & $(0.6)$ & 1.6 & $(0.2)$ & 9.4 & $(0.5)$ & 2.5 & $(0.2)$ \\
\hline Alcohol Dependence & 20.1 & $(1.0)$ & 10.7 & $(0.9)$ & 8.2 & $(0.7)$ & 3.7 & $(0.4)$ & 14.1 & $(0.7)$ & 7.2 & $(0.5)$ \\
\hline Drug Abuse & 5.4 & $(0.5)$ & 1.3 & $(0.2)$ & 3.5 & $(0.4)$ & 0.3 & $(0.1)$ & 4.4 & $(0.3)$ & 0.8 & $(0.1)$ \\
\hline Drug Dependence & 9.2 & $(0.7)$ & 3.8 & $(0.4)$ & 5.9 & $(0.5)$ & 1.9 & $(0.3)$ & 7.5 & $(0.4)$ & 2.8 & $(0.3)$ \\
\hline Any Addictive Disorder & 35.4 & (1.2) & 16.1 & $(0.7)$ & 17.9 & (1.1) & 6.6 & $(0.4)$ & 26.6 & $(1.0)$ & 11.3 & $(0.5)$ \\
\hline \multicolumn{13}{|l|}{ IV. Other Disorders } \\
\hline Antisocial Personality & 4.8 & $(0.5)$ & - & - & 1.0 & $(0.2)$ & - & - & 2.8 & $(0.2)$ & - & - \\
\hline Non-Affective Psychosis + & 0.3 & $(0.1)$ & 0.2 & $(0.1)$ & 0.7 & $(0.2)$ & 0.4 & $(0.1)$ & 0.5 & $(0.1)$ & 0.3 & $(0.1)$ \\
\hline V. Any NCS Disorders & 51.2 & (1.6) & 29.4 & $(1.0)$ & 48.5 & $(2.0)$ & 32.3 & (1.6) & 49.7 & $(1.2)$ & 30.9 & (1.0) \\
\hline
\end{tabular}

Reproduced from Kessler et al. (1994).

*se $=$ standard error.

+ Non-Affective Psychosis = schizophrenia, schizophreniform disorder, delusional disorder, and atypical psychosis.

- 12-month prevalence was not assessed.

more disorders in the 12 months prior to the interview. While there is no meaningful sex difference in these overall prevalences, there are sex differences in prevalences of specific disorders. Consistent with previous research (Helzer et al., 1991; Anthony \& Helzer, 1991), men are much more likely to have addictive disorders and ASPD than women, while women are much more likely to have affective disorders (with the exception of mania, for which there is no sex difference) and anxiety disorders than men. The data also show, consistent with a trend found in the ECA (Keith et al., 1991), that women in the household population are more likely to have nonaffective psychoses than men.

\section{Comorbidity}

Aggregate patterns of comorbidity: An important observation about the results in table $I$ is that the sum of the individual prevalence estimates across the disorders in each row consistently exceeds the prevalence of having any disorder in the last row. This means that there is a good deal of comorbidity among these disorders. For example, while the $49.7 \%$ lifetime prevalence in the total NCS sample means that 50 respondents out of every 100 in the sample reported a lifetime history of at least one disorder, a summation of lifetime prevalence estimates for the separate disorders shows that these 50 individuals reported a total of 102 lifetime disorders $(2.0$ per person). This comorbidity is quite important for understanding the distribution of psychiatric disorders in the US (Kessler, 1995). Although it is beyond the scope of this paper to delve into the many different types of comorbidity that exist in the population, some aggregate results are important to review.

The results in table II document that comorbidity is very important in understanding the distribution of psychiatric disorders among persons 15-54 in the US. These results also provide an empirical rationa- 
R.C. Kessler et al.

Table II. - The concentration of lifetime and 12-month CIDI/DSM-III-R disorders among persons with lifetime comorbidity in the NCS.

\begin{tabular}{|c|c|c|c|c|c|c|c|c|}
\hline & \multicolumn{2}{|c|}{$\begin{array}{l}\text { Proportion of } \\
\text { Sample }\end{array}$} & \multicolumn{2}{|c|}{$\begin{array}{c}\text { Proportion of } \\
\text { Lifetime Disorders }\end{array}$} & \multicolumn{2}{|c|}{$\begin{array}{l}\text { Proportion of } \\
\text { 12-Month Disorders }\end{array}$} & \multicolumn{2}{|c|}{$\begin{array}{l}\text { Proportion of Respondents } w / \\
\text { Severe 12-Month Disorders* }\end{array}$} \\
\hline & $\%$ & $\left(\mathrm{se}^{+}\right)$ & $\%$ & $\left(\mathrm{se}^{+}\right)$ & $\%$ & $\left(\mathrm{se}^{+}\right)$ & $\%$ & $\left(\mathrm{se}^{+}\right)$ \\
\hline \multicolumn{9}{|c|}{ Number of Lifetime Disorders } \\
\hline 0 & 52.0 & $(1.1)$ & - & - & - & - & - & - \\
\hline 1 & 21.0 & $(0.6)$ & 20.6 & $(0.6)$ & 17.4 & $(0.8)$ & 2.6 & $(1.7)$ \\
\hline 2 & 13.0 & $(0.5)$ & 25.5 & $(1.0)$ & 23.1 & $(1.0)$ & 7.9 & (2.1) \\
\hline 3 or more & 14.0 & $(0.7)$ & 53.9 & $(2.7)$ & 58.9 & $(1.8)$ & 89.5 & (2.8) \\
\hline
\end{tabular}

Reproduced from Kessler et al (1994).

* Severe 12-Month Disorders = active mania, NAP, or active disorders of other types that required hospitalization on created severe role impairment.

+ se $=$ standard error.

le for more detailed examination of particular types of comorbidity. The four rows of the table represent the number of lifetime disorders reported by respondents. The set of disorders considered here is somewhat smaller than in table I, accounting for the fact that $52 \%$ of respondents are estimated as never having any NCS/DSM-III-R disorder (which means that $48 \%$ are estimated to have one or more such disorders, which is smaller than the $49.7 \%$ in table I), $21 \%$ as having one, $13 \%$ two, and $14 \%$ three or more disorders. Only $21 \%$ of all the lifetime disorders occurred to respondents with a lifetime history of just one disorder. This means that the vast majority of lifetime disorders in this sample $(79 \%)$ are comorbid disorders. Furthermore, an even greater proportion of 12-month disorders occurred to respondents with a lifetime history of comorbidity. It is particularly striking that close to six out of every ten $(58.9 \%) 12$-month disorders and nearly nine out of ten $(89.5 \%)$ severe 12 -month disorders occurred to the $14 \%$ of the sample with a lifetime history of three or more disorders. These results show that while a history of some psychiatric disorder is quite common among persons 15-54 in the US, the major burden of psychiatric disorder in this sector of our society is concentrated in a group of highly comorbid people who constitute about one-sixth of the population.

Given this evidence, it is of some interest to learn more about detailed patterns of comorbidity. The ECA investigators were the first to do this in a community sample. They documented that comorbidity is widespread. Over $54 \%$ of ECA respondents with a lifetime history of at least one DSM-III psychiatric disorder were found to have a second diagnosis as well. Fifty-two percent $(52 \%)$ of lifetime alcohol abusers received a second diagnosis, and $75 \%$ of lifetime drug abusers had a second diagnosis (Robins et al., 1991). Respondents with a lifetime history of at least one mental disorder compared to respondents with no mental disorder had a relative-odds of 2.3 of having a lifetime history of alcohol abuse or dependence and a relative-odds of 4.5 of some other drug use disorder (Regier et al., 1990). Similar results were found in the NCS. Fifty-six percent $(56 \%)$ of the respondents with a lifetime history of at least one DSM-III-R disorder also had one or more other disorders (Kessler, in press). Fifty-two percent $(52 \%)$ of respondents with lifetime alcohol abuse or dependence also had a lifetime mental disorder, while $36 \%$ had a lifetime illicit drug use disorder. Fifty-nine percent $(59 \%)$ of the respondents with a lifetime history of illicit drug abuse or dependence, also had a lifetime mental disorder and $71 \%$ had a lifetime alcohol use disorder.

Detailed patterns of bivariate comorbidity: The results in table III show the proportions of people having each lifetime NCS/DSM-III-R disorder who reported at least one other lifetime disorder. As shown there, lifetime comorbidity is the norm, with proportions ranging from a low of $62.1 \%$ for alcohol abuse to a high of $99.4 \%$ for mania. The average proportion of comorbidity among disorders is $86.6 \%$. This does not mean that $86.6 \%$ of people with one or more lifetime disorders are comorbid, though, as those with comorbidity are counted multiple times in the table. Instead, $59.8 \%$ of the people who ever has one of the disorders considered in the NCS also had one or more other disorders.

Data on lifetime comorbidities of specific pairs of disorders in the NCS are reported in table IV. Results are shown in the form of odds-ratios (ORs). 
Table III. - Proportions with comorbidity among those with lifetime NCS/DSM-III-R disorders. ${ }^{\prime}$

\begin{tabular}{|c|c|c|c|}
\hline & & $\begin{array}{l}\text { Proportion with } \\
\text { Among Those }\end{array}$ & \multirow{2}{*}{$\begin{array}{l}\text { Lifetime Comorbidity } \\
\text { Having the Disorder } \\
\text { se }\end{array}$} \\
\hline & & $\%$ & \\
\hline \multirow[t]{5}{*}{ I. } & Mood Disorders & & \\
\hline & Major Depressive Episode & 83.1 & $(2.2)$ \\
\hline & Manic Episode & 99.4 & $(0.6)$ \\
\hline & Dysthymia & 91.3 & $(1.8)$ \\
\hline & Any Mood Disorder & 82.2 & (2.1) \\
\hline \multirow[t]{8}{*}{ II. } & Anxiety Disorders & & \\
\hline & Panic Disorder & 92.2 & $(1.9)$ \\
\hline & Agoraphobia & 87.3 & $(2.9)$ \\
\hline & Social Phobia & 81.0 & $(1.5)$ \\
\hline & Simple Phobia & 83.4 & $(1.5)$ \\
\hline & Generalized Anxiety Disorder & 91.3 & $(1.5)$ \\
\hline & Post-traumatic Stress Disorder & 81.0 & (3.3) \\
\hline & Any Anxiety Disorder & 74.1 & (1.5) \\
\hline \multicolumn{4}{|c|}{ III. Substance Use Disorders } \\
\hline & Alcohol Abuse & 62.1 & (2.6) \\
\hline & Alcohol Dependence & 80.6 & $(2.4)$ \\
\hline & Illicit Drug Use & 89.0 & (2.6) \\
\hline & Illicit Drug Dependence & 95.7 & $(2.0)$ \\
\hline & Any Addictive Disorder & 73.3 & (1.3) \\
\hline \multicolumn{4}{|c|}{ IV. Other Disorders } \\
\hline & Adult Antisocial Behavior & 96.2 & $(1.0)$ \\
\hline & Conduct Disorder & 78.9 & (2.6) \\
\hline & Nonaffective Psychosis & 93.0 & (4.4) \\
\hline & Any NCS Disorders & 59.8 & (1.2) \\
\hline
\end{tabular}

Reproduced from Kessler (in press).

${ }^{1}$ All disorders are operationalized using DSM-III-R criteria ignoring diagnostic hierarchy rules.

All but four of the 118 ORs are greater than 1.0. This means that there is a positive association between the lifetime occurrences of almost every pair of disorders considered here. However, there is considerable variation in the size of the ORs. It is conceivable that this variation is due to random error. In an effort to determine whether this is the case, a comparison was made between the ORs presented here and comparable ORs obtained by reanalyzing data from the ECA Study This comparison found a rank-order correlation between the two sets of ORs of. 79 (Kessler, 1995), which demonstrates that the variation in ORs is systematic rather than random.

Several patterns related to this variation are worthy of note. First, one would expect that the relative sizes of the ORs would show the disorders of a single type to be more strongly related to each other than to disorders of another type. This is generally true. For example, affective disorders are strongly related to other affective disorders. However, the strength of these pairwise associations among affective disorders is generally stronger than within the anxiety disorders, with an average OR of 13.5 for affective disorders compared to a much lower 6.2 for anxiety disorders. Second, most affective and anxiety disorders are strongly related to each other. In fact, pairwise associations between an affective disorder and an anxiety disorder (averaging 6.6) are generally stronger than between two anxiety disorders. Third, despite a substantial clinical literature pointing to the importance of comorbidity between mood disorders and substance use disorders (e.g., Allen \& Frances, 1986) and between anxiety disorders and substance use disorders (Roy et al., 1991), these are among the weakest comorbidities in the table (averaging 2.4).

One of the main purposes of investigating comorbid disorders is to help refine definitions of syndromes and diagnoses. With this in mind, it is important to recognize that some of the strongest ORs in the table are associated with clusters that are generally recognized as disorders in their own right. The largest OR in the table is between major depression and mania, a conjunction that represents bipolar disorder. Another very strong $O R$ is between mania and nonaffective psychosis, a conjunction that is part of the definition of schizoaffective disorder. There are also a number of strong ORs that are linked to discussions in the clinical literature of heretofore unrecognized disorders. For example, the suggestion has been made that comorbidity between major depression and manic is due to often due a phasic "panic-depressive illness" characterized by panic, depressive, and mixed anxious-depressive phases (Akiskal, 1986). This possibility is consistent with the finding of a very strong OR between panic and depression in the table.

Temporal priorities among comorbid disorders: Given the importance of comorbidity, a related question concerns which disorders in comorbid sets have the earliest ages of onset. The results in the first column of table $\mathrm{V}$ show that there is considerable variation across disorders in the probability of being the first lifetime disorder. Simple phobia, social phobia, alcohol abuse, and conduct disorder are the only for disorders considered here where the majority of lifetime cases are temporally primary in this way. In general, anxiety disorders are most likely to be temporally primary, with $82.8 \%$ of NCS respondents having one or more anxiety disorders reporting that one of these was their first lifetime disorder compared to $71.1 \%$ of those with conduct disorder, $43.8 \%$ of those with an affective disorder, and $48.1 \%$ of those with a substance use disorder. Results in the third column of the table show the per- 
Table IV. - Lifetime comorbidities (odds-ratios) between pairs of NCS/DSM-III-R disorders ${ }^{\text {. }}$.

\begin{tabular}{|c|c|c|c|c|c|c|c|c|c|c|c|c|c|c|c|}
\hline & \multirow[b]{2}{*}{$\mathrm{MDE}$} & \multicolumn{3}{|c|}{ Mood Disorders } & \multicolumn{4}{|c|}{ Anxiety Disorders } & \multicolumn{4}{|c|}{ Substance Use Disorders } & \multicolumn{3}{|c|}{ Other Disorders } \\
\hline & & $\mathrm{DD}$ & ME & $\mathrm{PD}$ & AG & SoP & SiP & GAD & PTSD & AA & $\mathrm{AD}$ & $\mathrm{DA}$ & DD & AAB & $\mathrm{CD}$ \\
\hline \multicolumn{16}{|c|}{ I. Mood Disorders } \\
\hline ME & $18.0^{*}$ & $8.2^{*}$ & & & & & & & & & & & & & \\
\hline DD & $14.4^{*}$ & - & & & & & & & & & & & & & \\
\hline \multicolumn{16}{|c|}{ II. Anxiety Disorders } \\
\hline PD & $7.0^{*}$ & $5.2^{*}$ & $11.0^{*}$ & - & - & - & - & $12.3^{*}$ & & & & & & & \\
\hline$A G$ & $4.8^{*}$ & $3.1^{*}$ & $7.9^{*}$ & $11.9^{*}$ & - & $7.1^{*}$ & $8.7^{*}$ & $5.8^{*}$ & & & & & & & \\
\hline SoP & $3.6^{*}$ & $3.1^{*}$ & $4.1^{*}$ & $4.8^{*}$ & - & - & - & $3.8^{*}$ & & & & & & & \\
\hline $\mathrm{SiP}$ & $4.5^{*}$ & $3.4^{*}$ & $10.1^{*}$ & $7.9^{*}$ & - & $7.8^{*}$ & - & $4.9^{*}$ & & & & & & & \\
\hline GAD & $9.7^{*}$ & $13.6^{*}$ & $10.4^{*}$ & - & - & - & - & - & & & & & & & \\
\hline PTSD & $5.3^{*}$ & $5.1^{*}$ & $6.1^{*}$ & $3.9^{*}$ & $4.2^{*}$ & $2.8^{*}$ & $3.8^{*}$ & $3.9^{*}$ & & & & & & & \\
\hline \multicolumn{16}{|c|}{ III. Substance Use Disorders } \\
\hline AA & 0.9 & 0.9 & 0.9 & 0.8 & 1.0 & 1.2 & $1.3^{*}$ & 1.0 & $0.7^{*}$ & & & & & & \\
\hline $\mathrm{AD}$ & $2.7^{*}$ & $3.0^{*}$ & $7.0^{*}$ & $2.7^{*}$ & $2.0^{*}$ & $2.2^{*}$ & $2.1^{*}$ & $1.7^{*}$ & $2.6^{*}$ & - & & & & & \\
\hline DA & $1.7^{*}$ & 1.4 & 1.1 & 1.5 & 1.6 & 1.2 & 1.1 & 0.9 & $1.6^{*}$ & $5.8^{*}$ & $3.8^{*}$ & & & & \\
\hline DD & $2.8^{*}$ & $3.0^{*}$ & $7.2^{*}$ & $3.8^{*}$ & $3.8^{*}$ & $2.6^{*}$ & $2.5^{*}$ & $2.9^{*}$ & $4.0^{*}$ & $2.3^{*}$ & $11.9^{*}$ & - & & & \\
\hline \multicolumn{16}{|c|}{ IV. Other Disorders } \\
\hline $\mathrm{AAB}$ & $2.4^{*}$ & $3.0^{*}$ & $7.3^{*}$ & $3.6^{*}$ & $2.2^{*}$ & $2.9^{*}$ & $2.5^{*}$ & $2.6^{*}$ & $3.5^{*}$ & $1.8^{*}$ & $10.7^{*}$ & $2.8^{*}$ & $13.7^{*}$ & - & $13.9^{*}$ \\
\hline$C D$ & $1.9^{*}$ & $2.0^{*}$ & $5.8^{*}$ & $1.8^{*}$ & $1.6^{*}$ & $2.1^{*}$ & $1.8^{*}$ & $1.9^{*}$ & $2.2^{*}$ & $2.0^{*}$ & $5.6^{*}$ & $2.6^{*}$ & $5.3^{*}$ & - & - \\
\hline NAP & $7.0^{*}$ & $4.2^{*}$ & $12.3^{*}$ & $6.1^{*}$ & $7.0^{*}$ & $3.0^{*}$ & $2.5^{*}$ & $4.0^{*}$ & $5.1^{*}$ & 1.1 & $3.3^{*}$ & 1.2 & $5.4^{*}$ & $9.3^{*}$ & $2.6^{*}$ \\
\hline
\end{tabular}

Reproduced from Kessler (1995)

* OR significant at the .05 level, two-tailed test

${ }^{1}$ All disorders are operationalized using DSM-III-R criteria ignoring diagnostic hierarchy rules. MDE = major depressive episode; DD $=$ dysthymia; $\mathrm{ME}=$ manic episode; $\mathrm{GAD}=$ generalized anxiety disorder; $\mathrm{PD}=$ panic disorder; $\mathrm{SoP}=$ social $\mathrm{phobia} ; \mathrm{SiP}=$ simple phobia; $\mathrm{AG}=$ agoraphobia; $\mathrm{PTSD}=$ post-traumatic stress disorder; $\mathrm{AA}=$ alcohol abuse; $\mathrm{AD}=$ alcohol dependence; $\mathrm{DA}=\mathrm{illicit}$ drug abuse; $\mathrm{DD}=$ illicit drug dependence; $\mathrm{CD}=$ conduct disorder; $\mathrm{AAB}=$ adult antisocial behavior (defined only for NCS respondents ages $19+$ and absent, by definition, for younger respondents); NAP = non-affective psychosis (schizophrenia, schizopreniform disorder, schizoaffective disorder, delusional disorder, atypical psychosis, psychosis NOS).

cent of overall respondents who reported each disorder as temporally primary. Once again we see that anxiety disorders are more likely to be temporally primary $(45.3 \%$ of all lifetime cases) than either affective disorders $(26.4 \%)$, substance use disorders $(24.5 \%)$, or other disorders $(19.5 \%)$.

Predictively primary disorders: It is a mistake to think of temporal priority as equivalent to causal priority, as it is possible to have comorbid disorders in which the disorder with the earlier age of onset does not significantly predict the subsequent onset of the second disorder (Kessler \& Price, 1993). A more useful way to begin examining the possibility of causal priority is to investigate predictive priority; whether one disorder is significantly associated with the subsequent onset of another disorder. This was done in the NCS by using retrospective age of onset reports for each disorder to estimate a series of bivariate survival models in which onset of that disorder was treated as a time-varying predictor of the other disorders (Efron, 1988). (NAP was not included in the analysis because of low prevalence). These models constrained the ef- fects of earlier disorders to be constant across age of onset, time since onset, and age of onset of the outcome disorder. Despite these unrealistic simplifying assumptions, the results provide useful first approximations of the average effects of earlier disorders in predicting the onset of later disorders.

Results are reported in table VI. One hundred sixty-six of the 201 coefficients in the table are statistically significant, all of them with ORs greater than 1.0. This means that most NCS/DSM-III-R disorders both significantly predict the subsequent onset of other disorders and are significantly predicted by prior disorders. Thirteen of the 15 disorders considered here are pervasive predictors; that is, they significantly predict the vast majority (between 10 and 14) of the other disorders. The exceptions are alcohol abuse (AA), which predicts only three other disorders, and illicit drug abuse (DA), which predicts only seven. Twelve of the disorders are also pervasively predicted (by between 11 and 14 of the other disorders). The exceptions are AA, which is predicted by only four other disorders, drug abuse, which is pre- 
Table V. - Percent temporally primary and distribution of temporally primary NCS/DSM-III-R disorders. ${ }^{I}$

\begin{tabular}{|c|c|c|c|c|}
\hline & \multicolumn{2}{|c|}{$\begin{array}{l}\text { Percent Temporally } \\
\text { Primary Among Those } \\
\text { Having the Disorder }\end{array}$} & \multicolumn{2}{|c|}{$\begin{array}{c}\text { Distribution } \\
\text { of Temporally } \\
\text { Primary }\end{array}$} \\
\hline & $\%$ & se & $\%$ & se \\
\hline \multicolumn{5}{|l|}{ I. Mood Disorders } \\
\hline Major Depressive Episode & 41.1 & $(2.7)$ & 13.4 & $(0.9)$ \\
\hline Manic Episode & 20.2 & $(6.0)$ & 0.7 & $(0.2)$ \\
\hline Dysthymia & 37.7 & $(3.1)$ & 4.8 & $(0.5)$ \\
\hline Any Mood Disorder & 43.8 & $(2.4)$ & 16.4 & $(0.9)$ \\
\hline \multicolumn{5}{|l|}{ II. Anxiety Disorders } \\
\hline Panic Disorder & 23.3 & $(3.2)$ & 1.6 & $(0.2)$ \\
\hline Agoraphobia & 45.2 & $(4.0)$ & 5.9 & $(0.7)$ \\
\hline Social Phobia & 63.1 & $(2.0)$ & 16.0 & $(0.9)$ \\
\hline Simple Phobia & 67.6 & $(2.7)$ & 14.5 & $(1.0)$ \\
\hline Generalized Anxiety Disorder & 37.0 & $(2.9)$ & 3.6 & $(0.4)$ \\
\hline Post-traumatic Stress Disorder & 52.1 & $(3.0)$ & $7-5$ & $(0.7)$ \\
\hline Any Anxiety Disorder & 82.8 & $(1.3)$ & 45.3 & $(1.4)$ \\
\hline \multicolumn{5}{|l|}{ III. Substance Use Disorders } \\
\hline Alcohol Abuse & 57.0 & $(2.3)$ & 10.2 & $(0.6)$ \\
\hline Alcohol Dependence & 36.8 & $(3.1)$ & 9.9 & $(0.6)$ \\
\hline Illicit Drug Abuse & 39.7 & $(3.0)$ & 3.4 & $(0.3)$ \\
\hline Illicit Drug Dependence & 20.8 & $(2.5)$ & 3.0 & $(0.3)$ \\
\hline Any Addictive Disorder & 48.1 & $(1.6)$ & 24.5 & $(1.0)$ \\
\hline \multicolumn{5}{|l|}{ IV. Other Disorders } \\
\hline Adult Antisocial Behavior & 14.0 & $(1.8)$ & 1.4 & $(0.2)$ \\
\hline Conduct Disorder & 71.1 & $(2.0)$ & 17.7 & $(1.0)$ \\
\hline Nonaffective Psychosis & 28.8 & $(5.6)$ & 0.4 & $(0.1)$ \\
\hline
\end{tabular}

Reproduced from Kessler (in press).

${ }^{1}$ All disorders are operationalized using DSM-III-R criteria ignoring diagnostic hierarchy rules.

dicted by nine other disorders, and conduct disorder, which is predicted by six other disorders.

There are a number of significant asymmetries in the ORs. Mood disorders generally predict anxiety disorders (average OR $=6.4$ ), substance use disorders (average $\mathrm{OR}=3.5$ ), and $\mathrm{CD} / \mathrm{AAB}$ (average $\mathrm{OR}=4.3$ ) more strongly than the latter predict mood disorders (average ORs of 4.0, 2.3, and 3.6, respectively). Anxiety disorders generally predict alcohol and drug dependence (average OR $=2.9$ ) more strongly than the latter predict anxiety (average $\mathrm{OR}=2.3$ ). And substance use disorders generally predict $\mathrm{CD} / \mathrm{AAB}$ (average $\mathrm{OR}=7.4$ ) more strongly than the latter predict substance use disorders (average $\mathrm{OR}=5.3$ ).

\section{Use of services}

Only a minority of those with a lifetime NCS/ DSM-III-R disorder $(42.0 \%)$ reported ever obtai- ning professional treatment for their problems. The proportions treated in the mental health specialty sector $(26.2 \%)$ or in a substance abuse treatment setting $(8.4 \%)$ are even smaller. Only about one-fifth of respondents who reported an episode of a disorder during the year before interview obtained any professional treatment and only about half of those people were seen in a mental or addictive disorders specialty setting. These results are quite consistent with those of the ECA Study (Regier et al., 1993) and suggest that there is considerable unmet need for services. It is worth noting, though, that there are strong relationships of number and severity of disorders with probability of obtaining professional help, which suggests that probability of obtaining treatment is higher for those whose need is greatest.

\section{Social consequences}

Recent debates in the US concerning the place of mental health coverage in health care reform has led to a new interest on the part of American psychiatric epidemiologists in the social consequences of psychiatric disorders. A number of recent studies of this issue have documented that psychiatric disorders have substantial personal costs for the individuals who experience them as well as for their families and communities in terms of both finances and role functioning (Wohlfarth et al., 1993; Wells et al., 1989; Rhode et al., 1990). Data from the ECA showed that people with psychiatric disorders have considerably more work loss days than others (Johnson et al., 1992; Broadhead et al., 1990), a result replicated in the NCS. NCS analyses also showed that early-onset psychiatric disorders are strongly related to subsequent teen childbearing, school dropout, marital instability, and long-term financial adversity (Kessler et al., 1995; under review; Kessler \& Forthofer, under review). These results document hidden societal costs of psychiatric disorders not only in the indirect sense of threats to our ability to maintain an educated and well functioning citizenry and work force, but also in the direct sense that the outcomes documented here are associated with increased use of entitlement programs such as unemployment and welfare that are paid for by all taxpayers. These societal costs need to be taken into consideration in policy evaluations of the societal cost-benefit ratios of providing mental health treatment irrespective of ability to pay compared to the costs of failing to do so. 
Table VI. - The associations (odds-ratios) between lifetime history of one NCS/DSM-III-R disorder (rows) and subsequent first onset of other disorders (columns)!

\begin{tabular}{|c|c|c|c|c|c|c|c|c|c|c|c|c|c|c|c|}
\hline & \multicolumn{4}{|c|}{ Mood Disorders } & \multicolumn{5}{|c|}{ Anxiety Disorders } & \multicolumn{4}{|c|}{ Substance Use Disorders } & \multicolumn{2}{|c|}{ Other Disorders } \\
\hline & MDE & ME & DD & PD & AG & SoP & $\mathrm{SiP}$ & GAD & PTSD & AA & $\mathrm{AD}$ & DA & DD & AAB & $\mathrm{CD}$ \\
\hline \multicolumn{16}{|c|}{ I. Mood Disorders } \\
\hline MDE & - & $7.7^{*}$ & $3.5^{*}$ & $5.1^{*}$ & $3.4^{*}$ & $2.9^{*}$ & $3.1^{*}$ & $3.4^{*}$ & $6.7^{*}$ & 1.3 & $3.3^{*}$ & $2.9^{*}$ & $4.3^{*}$ & $4.2^{*}$ & $3.3^{*}$ \\
\hline ME & $8.7^{*}$ & - & $7.3^{*}$ & $10.8^{*}$ & $12.4^{*}$ & $5.3^{*}$ & $16.8^{*}$ & $12.8^{*}$ & $8.2^{*}$ & 0.8 & $9.0^{*}$ & 2.1 & $9.1^{*}$ & $8.5^{*}$ & $215.4^{*}$ \\
\hline DD & $5.2^{*}$ & $5.9^{*}$ & - & $3.6^{*}$ & $2.5^{*}$ & $2.8^{*}$ & $3.1^{*}$ & $5.4^{*}$ & $6.9^{*}$ & 0.9 & $3.6^{*}$ & $2.1^{*}$ & $3.1^{*}$ & $3.3^{*}$ & 2.3 \\
\hline \multicolumn{16}{|c|}{ II. Anxiety Disorders } \\
\hline PD & $3.5^{*}$ & $13.7^{*}$ & $5.1^{*}$ & - & $2.5^{*}$ & 1.6 & $2.2^{*}$ & $5.7^{*}$ & $4.9^{*}$ & 0.7 & $3.2^{*}$ & 1.4 & $5.2^{*}$ & $5.5^{*}$ & $3.7^{*}$ \\
\hline $\mathrm{AG}$ & $3.4^{*}$ & $2.8^{*}$ & $2.3^{*}$ & $5.0^{*}$ & - & $3.4^{*}$ & $4.3^{*}$ & $2.9^{*}$ & $4.5^{*}$ & 1.3 & $2.1^{*}$ & 1.1 & $3.3^{*}$ & $3.7^{*}$ & $2.4^{*}$ \\
\hline SoP & $2.9^{*}$ & $2.4^{*}$ & $3.0^{*}$ & $4.3^{*}$ & $3.8^{*}$ & - & $4.5^{*}$ & $2.4^{*}$ & $2.4^{*}$ & $1.5^{*}$ & $2.2^{*}$ & $1.6^{*}$ & $2.8^{*}$ & $2.9^{*}$ & $2.0^{*}$ \\
\hline $\mathrm{SiP}$ & $2.9^{*}$ & 0.9 & $3.3^{*}$ & $2.7^{*}$ & $2.9^{*}$ & $3.4^{*}$ & - & $2.0^{*}$ & $1.8^{*}$ & $1.4^{*}$ & $2.1^{*}$ & 1.1 & $3.0^{*}$ & $2.6^{*}$ & $1.1^{*}$ \\
\hline GAD & $4.0^{*}$ & $4.9^{*}$ & $7.1^{*}$ & $6.9^{*}$ & $4.3^{*}$ & $5.9^{*}$ & $3.8^{*}$ & - & $4.9^{*}$ & 1.1 & $2.9^{*}$ & $2.4^{*}$ & $4.7^{*}$ & $4.6^{*}$ & 0.9 \\
\hline PTSD & $2.7^{*}$ & $2.7^{*}$ & $3.7^{*}$ & $2.2^{*}$ & $2.4^{*}$ & $1.9^{*}$ & $2.8^{*}$ & $2.2^{*}$ & - & 0.7 & $2.4^{*}$ & $1.7^{*}$ & $4.0^{*}$ & $3.0^{*}$ & $1.9^{*}$ \\
\hline \multicolumn{16}{|c|}{ III. Substance Use Disorders } \\
\hline AA & 1.0 & 1.1 & 1.0 & 1.5 & 1.0 & 0.7 & 1.1 & 0.9 & 0.6 & - & -2 & $4.5^{*}$ & $3.2^{*}$ & $2.6^{*}$ & $-{ }^{3}$ \\
\hline $\mathrm{AD}$ & $2.0^{*}$ & $5.4^{*}$ & $2.0^{*}$ & $1.6^{*}$ & $1.6^{*}$ & $2.2^{*}$ & 1.4 & $2.3^{*}$ & $2.6^{*}$ & $-^{2}$ & - & $3.0^{*}$ & $8.2^{*}$ & $17.0^{*}$ & $-{ }^{3}$ \\
\hline DA & $1.4^{*}$ & 0.9 & 1.3 & $2.3^{*}$ & 1.7 & 0.7 & $1.8^{*}$ & 1.2 & $1.8^{*}$ & $2.5^{*}$ & $3.4^{*}$ & - & -2 & $3.2^{*}$ & $-{ }^{3}$ \\
\hline DD & $2.0^{*}$ & $6.3^{*}$ & $3.0^{*}$ & $3.6^{*}$ & $2.6^{*}$ & $2.4^{*}$ & 1.2 & $2.9^{*}$ & $2.9^{*}$ & 1.0 & $5.6^{*}$ & $-{ }^{2}$ & - & $17.0^{*}$ & $-{ }^{3}$ \\
\hline \multicolumn{16}{|c|}{ IV. Other Disorders } \\
\hline AAB & $2.0^{*}$ & $6.4^{*}$ & $3.5^{*}$ & $2.0^{*}$ & $2.1^{*}$ & $2.9^{*}$ & $2.8^{*}$ & $3.5^{*}$ & $4.3^{*}$ & 1.1 & $5.2^{*}$ & $2.1^{*}$ & $8.5^{*}$ & - & -4 \\
\hline $\mathrm{CD}$ & $2.1^{*}$ & $5.6^{*}$ & $2.3^{*}$ & $1.6^{*}$ & $1.7^{*}$ & $1.9^{*}$ & $2.0^{*}$ & $2.1^{*}$ & $2.2^{*}$ & $2.0^{*}$ & $5.2^{*}$ & $2.6^{*}$ & 5.3 & $14.5^{*}$ & - \\
\hline
\end{tabular}

Reproduced from Kessler (in press).

* OR significant at the .05 level, two-tailed test.

${ }^{1}$ All disorders are operationalized using DSM-III-R criteria ignoring diagnostic hierarchy rules. MDE = major depressive episode; DD $=$ dysthymia; $\mathrm{ME}=$ manic episode; $\mathrm{GAD}=$ generalized anxiety disorder; $\mathrm{PD}=$ panic disorder; $\mathrm{SoP}=$ social phobia; $\mathrm{SiP}=$ simple phobia; AG = agoraphobia; PTSD = post-traumatic stress disorder; $\mathrm{AA}=$ alcohol abuse; $\mathrm{AD}=$ alcohol dependence; $\mathrm{DA}=\mathrm{illicit}$ drug abuse; $\mathrm{DD}=$ illicit drug dependence; $\mathrm{CD}=$ conduct disorder; $\mathrm{AAB}=$ adult antisocial behavior (defined only for NCS respondents ages $19+$ and absent, by definition, for younger respondents); NAP = non-affective psychosis (schizophrenia, schizopreniform disorder, schizoaffective disorder, delusional disorder, atypical psychosis, psychosis NOS).

${ }^{2}$ Substance abuse and dependence do not overlap by definition.

${ }^{3}$ Age of onset of CD was not assessed in the NCS and is arbitrarily set at 10 for purposes of the analyses reported in this table. The ORs in the CD column consequently describe the associations between having other disorders prior to age 10 and having CD. The ORs for substance use disorders could not be computed because of the small numbers of respondents who reported the onset of these disorders

\section{OVERVIEW}

It is instructive to compare the NCS prevalence estimates with the results of the ECA Study (Robins \& Regier, 1991). As noted above, the ECA was carried out in five communities around the country and the results were subsequently combined and weighted to the population distribution of the US on the cross-classification of age, sex, and race in an effort to make national estimates (Regier et al., 1993). To the extent that this post-stratification succeeded in adjusting for the lack of representativeness of the local samples, it should be possible to make valid comparisons between the ECA and NCS results. A limitation in doing this is that the ECA was based on an unrestricted age range of adults while the NCS was based on the 15-54 age range. Another limitation is that the ECA diagnoses were based on DSM-III criteria (American Psychiatric Association, 1980), while the NCS diagnoses were based on DSM-III-R criteria (American Psychiatric Association, 1987). These two diagnostic systems differ substantially in a number of respects.

In order to resolve these problems, collaborative ECA-NCS comparative analyses have been carried out in which subsamples in the 18-54 age range in both samples were compared using common measures that operationalize DSM-III criteria (which can be reconstructed from the NCS data, although DSM-III-R criteria cannot be reconstructed from the ECA data). The as yet unpublished results show that the NCS prevalence estimates are considerably higher than the baseline ECA estimates (Regier et 
$a l$. , under review). However, overall prevalences are quite similar in the NCS and ECA when the NCS is compared with the revised estimates obtained from the two-wave consolidated ECA data (Regier et al., 1993). This reconciliation occurs because the ECA prevalence estimates increase substantially when the results from the two separate survey waves are consolidated as they were by Regier and his colleagues. They made this consolidation in an effort to reduce the underreporting bias in the cross-sectional ECA results and, in this way, obtain more valid estimates of the 12-month population prevalence of psychiatric disorders.

The fact that the cross-sectional NCS estimates are similar to those based on the consolidated ECA analysis is due to the use of special memory enhancement and motivation procedures in the NCS to address the problem of underreporting bias (Kessler et al., in press a). Evidence from an as-yet unpublished panel survey by Jay Turner and collaborators in Toronto (personal communication, April 3, 1995) shows that the increase in prevalence estimates when two waves of data are combined is much smaller when the first wave uses the NCS memory enhancement and motivation procedures, a result which suggests that these procedures lead to a substantial reduction in underreporting bias in the baseline survey.

A question can be raised whether these high prevalence estimates are due to overestimation of disorders in the lay-administered CIDI. This appears not to be the case. WHO Field Trials documented good validity of the CIDI and no evidence of overestimation of the prevalences of common disorders (Wittchen, 1994). In addition, NCS validity studies show that the vast majority of diagnoses made in the NCS are confirmed by blind clinical reinterview (Wittchen et al., 1995; in press). This being the case, the results are most reasonably interpreted as showing that psychiatric disorders are genuinely quite common in the general population, with a majority of people meeting criteria for at least one of these disorders at some time in their life.

Although such a result might initially seem remarkable, it is actually quite easy to understand. The DSM classification system is very broad. It includes a number of disorders that are usually self-limiting and not severely impairing. It should be no more surprising to find that half the population has met criteria for one or more of these disorders in their life than to find that the vast majority of the population has had the flu or measles or some other common physical malady at some time in their life. The more surprising result is that while many people have been touched by mental illness at some time in their life, the major burden of psychiatric disorder in the population is concentrated in the relatively small subset of people who are highly comorbid. This means that a pile-up of multiple disorders is the most important defining characteristic of serious mental illness.

\section{FUTURE DIRECTIONS}

The finding regarding the importance of comorbidity leads to the focus of our current work on the primary prevention of secondary disorders (Kessler \& Price, 1993); that is, on the prevention of the onset of secondary disorders in the wake of primary disorders. The NCS results suggest that this type of prevention effort could result in an enormous decrease in the existence of serious and severe psychiatric disorders as well as a decrease in the adverse social consequences of psychiatric disorders. Based on our results so far regarding the feasibility of such prevention efforts, it appears that primary anxiety disorders and primary conduct disorder are the most promising intervention targets (Kessler et al., $1996 \mathrm{a}, \mathrm{b}$, in press b) and that the window of opportunity for such interventions is in the decade between the early teenage years and the early twenties. Analyses aimed at cross-validating results regarding modifiable risk factors for the onset of secondary disorders are currently underway along with plans for a follow-up of the NCS sample in order to confirm currently retrospective results with prospective data as preliminaries to the design and implementation of targeted interventions.

In addition, we are keen to extend our results regarding cohort effects for the disorders considered in the NCS, especially the results regarding increases in recent cohorts involving primary anxiety and addictive disorders and secondary mood disorders. These results suggest that the prevalences of anxiety and addictive disorders have increased among young people in the cohorts born after World War II. These increases have been associated with subsequent increases in the prevalence of secondary mood disorders, but not primary mood disorders. These results could be very important, but it is not clear how seriously we should take them in light of the fact that they are based on retrospective reports. If they are true, though, we would expect to find two types of 
related patterns in other countries. First, we would expect differential evidence for similar intercohort patterns of change in primary anxiety disorders and mood disorders that occur secondary to anxiety disorders in other countries, depending on the extent to which these countries were involved in World War II and the societal changes it created. Second, we would expect to find a time lag in the increase in mood disorders secondary to primary addictive disorders depending on whether the introduction of drug use into teenage culture occurred for the first time in: i) the earliest post-War cohorts (as in the US), ii) in somewhat later post-War cohorts (as in Western Europe), iii) or only in more recent cohorts (as in South America and Eastern Europe). In an effort to evaluate these cross-national hypotheses, we have formed an International Consortium in Psychiatric Epidemiology (ICPE) that has come together to create a comparative international database from a series of surveys like the NCS that either have been carried out over the past few years, or are in the process of being carried out in close to two dozen countries around the world. All of these surveys have used or will use some version of the CIDI to generate diagnoses, and all are based on community samples. This work is being carried out in collaboration with the World Health Organization under the supervision of Professor Bedirhan Ustun. Investigators from eleven countries currently having data available for analysis are participating in the first wave of ICPE investigations, with others to follow as their data become available. The first wave of collaborating investigators include: Sergio Aguilar-Gaxiola (US), Margarita Alegria (Puerto Rico), Laura Andrade (Brazil), Gavin Andrews (Australia), Jan Beals (US), Rob Bijl (Netherlands), Jorge CaraveoAnduaga (Mexico), Scott Henderson (Australia), Cengiz Kilic (Turkey), Spero Manson (US), Maria Elena Medina-Mora (Mexico), Ivan Montoya (Columbia), Dan Offord (Canada), David Takeuchi (US), R. Jay Turner (Canada), Gertjan van Zessen (Netherlands), William Vega (US), Benjamin Vincente (Chile), and Hans-Ulrich Wittchen (Germany). Although no Italian investigators are as yet part of the consortium, we would greatly value the inclusion of a community-based epidemiologic survey from Italy in the next wave of ICPE studies.

Acknowledgments. The National Comorbidity Survey (NCS) is a collaborative epidemiologic investigation of the prevalence, causes, and consequences of psychiatric morbidity and comorbidity in the United States supported by the National Institute of Mental Health with supplemental support from the National Institute of
Drug Abuse (Grants R01 MH46376, RO1 MH52861 and R01 MH49098) and additional support from the W.T. Grant Foundation (Grant 90135190), Ronald C. Kessler, Principal Investigator. Preparation for this report was also supported by Research Scientist Awards K05 MH01277 to Kessler and K05 MH00507 to Kendler and by Training Grant T32 MH16806. Collaborating NCS sites and investigators are: The Addiction Research Foundation (Robin Room), Duke University (Dan Blazer, Marvin Swartz), Harvard University (Richard Frank, Ronald Kessler), Johns Hopkins University (James Anthony, William Eaton, Philip Leaf), The University of Miami (R. Jay Turner), The Max Planck Institute of Psychiatry - Clinical Institute (Hans-Ulrich Wittchen), The Medical College of Virginia (Kenneth Kendler), the University of Michigan (Lloyd Johnston), New York University (Patrick Shrout), SUNY Stony Brook (Evelyn Bromet), and Washington University (Linda Cottler, Andrew Heath). A complete list of NCS publications and study documentation along with a copy of the public use NCS data can be obtained can be obtained directly from the NCS Homepage by using the URL: http://www.umich.edu/ ncsum/.

\section{REFERENCES}

Akiskal H.S. (1986). Mood disturbances. In The Medical Basis of Psychiatry (ed. G. Winokur \& P. Clayton), pp. 365-380. W.B. Saunders: Philadelphia.

Allen M.H. \& Frances R.M. (1986). Varieties of psychopathology found in patients with addictive disorders: a review. In Psychopathology and Addictive Disorders (ed. R.E. Meyer), pp. 17-38. Guilford Press: New York.

Alluglander C. (1989). Psychoactive drug use in a general population sample, Sweden: correlates with perceived health, psychiatric diagnoses, and mortality in an automated record-linkage study. American Journal of Public Health 79, 1006-1010.

American Psychiatric Association (1980). Diagnostic and Statistical Manual of Mental Disorders. APA: Washington, DC.

American Psychiatric Association (1987). Diagnostic and Statistical Manual of Mental Disorders, 3rd ed. revised. APA: Washington, DC.

Anthony J.C. \& Helzer J.E. (1991). Syndromes of drug abuse and dependence. In Psychiatric Disorders in America: the Epidemiologic Catchment Area Study (ed. L.N. Robins and D.A. Regier), pp. 116-154. Free Press: New York.

Anthony J.C., Folstein M., Romanoski A.J., VonKorff M.R., Nestadt G.R., Chahal R., Merchant, A. Brown, C.H. Shapiro, S. Kramer \& Gruenberg E.M. (1985). Comparison of the lay Diagnostic Interview Schedule and a standardized psychiatric diagnosis: experience in Eastern Baltimore. Archives of General Psychiatry 42, 667-675.

Bourdon K.H., Rae D.A., Locke B.Z., Narrow W.E. \& Regier D.A. (1992). Estimating the prevalence of mental disorders in U.S. adults from the Epidemiologic Catchment Area Study. Public Health Reporter 107, 663-668.

Broadhead W.E., Blazer D.G., George L.K., \& Kit T.C. (1990). Depression, disability days, and days lost from work in a prospective epidemiologic survey. Journal of American Medicine 264, 2524-2528.

Eaton W.W., Anthony J.C., Tepper S. \& Dryman A. (1992). Psy- 
chopathology and attrition in the Epidemiologic Catchment Area Study. American Journal of Epidemiology 135, 1051-1059.

Efron B. (1988). Logistic regression, survival analysis, and the Kaplan-Meier curve. Journal of American Statistical Association $83,414-425$.

Endicott J. \& Spitzer R. (1978). Family History Research Diagnostic Criteria. Biometrics Research. New York State Psychiatric Institute: New York.

Helzer J.E., Robins L.N., McEvoy L.T. \& Spitznagel E.A. (1985). Comparison of clinical and Diagnostic Interview Schedule diagnoses. Archives of General Psychiatry 42, 657-666.

Helzer J.E., Burnam A. \& McEvoy L.T. (1991). Alcohol abuse and dependence. In Psychiatric Disorders in America: the Epidemiologic Catchment Area Study (ed. L.N. Robins and D.A. Regier), pp.81-115. Free Press: New York.

Johnson J., Weissman M.M., \& Klerman G.L. (1992). Service utilization and social morbidity associated with depressive symptoms in the community. Journal of American Medicine 267, 1478-1483.

Keith S.J., Regier D.A. \& Rae D.S. (1991). Schizophrenic disorders. In Psychiatric Disorders in America: the Epidemiologic Catchment Area Study (ed. D.A. Regier and L.N. Robins), pp. 33-52. Free Press: New York.

Kendler K.S., Gallagher T.J., Abelson J.M., \& Kessler R.C. (in press). Lifetime prevalence, demographic risk factors and diagnostic validity of nonaffective psychosis as assessed in a U.S. community sample: the National Comorbidity Survey. Archives of General Psychiatry 51, 8-19.

Kessler R.C. (1995). The epidemiology of psychiatric comorbidity. In Textbook of Psychiatric Epidemiology (ed. M. Tsuang, M. Tohen and G. Zahner), pp. 179-198. Wiley \& Sons: New York.

Kessler R.C. (in press). The prevalence of psychiatric comorbidity. In Treatment Strategies for Patients with Psychiatric Comorbidity (ed. S. Wetzler and W.C. Sanderson). John Wiley \& Sons: New York.

Kessler R.C. \& Forthofer M.S. (under review). The social consequences of psychiatric disorders. III: Marriage and marital stability. American Journal of Psychiatry.

Kessler R.C. \& Price R.H. (1993). Primary prevention of secondary disorders: A proposal and agenda. American Journal of Community Psychology 21, 607-634.

Kessler R.C., McGonagle K.A., Zhao S., Nelson C.B., Hughes M., Eshleman S., Wittchen H.-U. \& Kendler K.S. (1994). Lifetime and 12-month prevalence of DSM-III-R psychiatric disorders in the United States: Results from the National Comorbidity Survey. Archives of General Psychiatry 51, 8-19.

Kessler R.C., Foster C.L., Saunders W.B. \& Stang P.E. (1995). Social consequences of psychiatrict disorders. I: Educational attainment. American Journal of Psychiatry 152, 1026-1032.

Kessler R.C., Nelson C.B., McGonagle K.A., Liu J., Swartz M. \& Blaxer D.G. (1996a). Comorbidity of DSM-III-R Major Depressive Disorder in the general population: results from the US National Comorbidity Survey. British Journal of Psychiatry 168, 8-21.

Kessler R.C., Nelson C.B., McGonagle K.A., Edlund M.J., Frank R.G. \& Leaf P.J. (1996b). The epidemiology of co-occurring addictive and mental disorders in the National Comorbidity Survey: Implications for prevention and service utilitization. American Journal of Orthopsychiatry 66, 17-31.

Kessler R.C., Mroczek D.K. \& Belli R.F. (in press a). Retrospective adult assessment of childhood psychopathology. In Assessment in Childhood Psychopathology (ed. D. Shaffer and J. Richters). Guildford Press: New York.
Kessler R.C., Crum R.M., Warner L.A., Nelson C.B., Schulenbeg J. \& Anthony J.C. (in press b). The lifetime co-occurrence of DSM-III-R alcohol abuse and dependence with other psychiatric disorders in the National Comorbidity Survey. Archives of General Psychiatry.

Kessler R.C., Foster C.L., Saunders W.B. \& Stand P.E. (under review). The social consequences of psychiatric disorders. II: Teenage childbearing. American Journal of Psychiatry.

Koch G.G. \& Leneshow S. (1972). An application of multivariate analysis to complex sample survey data. Journal of the American Statistical Association 67, 780-782.

President's Commission on Mental Health and Illness. (1978). Report to the President from the President's Commission on Mental Health, Vol. 1. US Government Printing Office: Washington DC.

Regier D.A., Farmer M.E., Rae DS., Locke B.Z., Keith B.J., Judd L.L. \& Godwin, F.K. (1990). Comorbidity of mental health disorders with alcohol and other drug abuse. Journal of the American Medical Association 264, 2511-2518.

Regier D.A., Narrow W.E., Rae D.S., Manderscheid R.W., Locke B.Z. \& Goodwin F.K. (1993). The de Facto US Mental and Addictive Disorders Service System: Epidemiologic Catchment Area prospective 1-year prevalence rates of disorders and services. Archives of General Psychiatry 50, 85-94.

Regier D.A., Kaelber C.T., Rae D.S., Farmer M.E., Knauper B., Kessler R.C. \& Norquist G.S. (under review). Limitations of diagnostic criteria and assessment instruments for mental disorders: Implications for research policy.

Rhode P., Lewinsohn P. \& Seeley J. (1990). Are people changed by the experience of having an episode of depression? A further test of the scar hypothesis. Journal of Abnormnal Psychology 99, 264-271.

Robins L.N. \& Regier D.A. (1991). Psychiatric Disorders in America: The Epidemiologic Catchment Area Study. Free Press: New York.

Robins L.N., Helzer J.E., Croughan J.L. \& Ratcliff K.S. (1981). National Institute of Mental Health Diagnostic Interview Schedule: its history, characteristics and validity. Archives of General Psychiatry 38, 381-389.

Robins L.N., Wing J., Wittchen H.-U. \& Helzer J. E. (1988). The Composite International Diagnostic Interview. An epidemiologic instrument suitable for use in conjunction with different diagnostic systems and in different cultures. Archives of General Psychiatry 45, 1069-1077.

Robins L.N., Locke B.Z. \& Regier D.A. (1991). An overview of psychiatric disorders in America. In Psychiatric Disorders in America: the Epidemiologic Catchment Area Study (ed. L.M. Robins and D.A. Regier), pp.328-366. Free Press: New York.

Roy A., DeJong J., Lamparski D., Adinof B., George T., Moore V., Garnett D., Kerich M. \& Linnoila M. (1991). Mental disorders among alcoholics: Relationship to age of onset and cerebrospinal fluid neuropeptides. Archives of General Psychiatry $48,428-432$.

SAS Institute (1988). SAS 6.03. SAS Institute: Cary, NC.

Spitzer R.L., Williams J.B.W., Gibbon M. \& First M.B. (1992). The structured clinical interview for DSM-III-R (SCID), I: history, rationale, and description. Archives of General Psychiatry 49, 624-629.

University of Michigan (1981). OSIRIS VII. Institute for Social Research, University of Michigan: Ann Arbor, Michigan.

United States Department of Health and Human Services (1992). National Health Interview Survey: 1989 (Computer File). National Center for Health Statistics: Hyattsville, MD. 
Wells K., Stewart A., Hays R., Burnam M., Rogers W., Daniels M., Berry S., Greenfield S. \& Ware J. (1989). The functioning and well-being of depressed patients: results from the Medical Outcomes Study. Journal of American Medicine 262, 914-919.

Williams J.B.W., Gibbon M., First M.B., Spitzer R.L., Davis M., Borus J., Howes M.J., Kane J., Harrison G.P. Jr., Rounsaville B. \& Wittchen H.-U. (1992). The structured clinical interview for DSM-III-R (SCID), II: multsite test-retest reliability. $\mathrm{Ar}$ chives of General Psychiatry 49, 630-636.

Wittchen H.-U. (1994). Reliability and validity studies of the WHO-Composite International Diagnostic Interview (CIDI): a critical review. Journal of Psychiatric Research 28, 57-84.

Wittchen H.-U., Kessler R.C., Zhao S. \& Abelson J. (1995). Reliability and clinical validity of UM-CIDI DSM-III-R generalized anxiety disorder. Journal of Psychiatric Research 29, 95-110.

Wittchen H.-U., Zhao S., Abelson J.M., Abelson J.L. \& Kessler
R.C. (in press). Reliability and procedural validity of UM-CIDI DSM-III-R phobic disorders. Psychological Medicine.

Wohlfarth T.D., van den Brink W., Ormel J., Koeter M.W. \& Oldhinkel A.J. (1993). The relationship betwen social dysfunctioning and psychopathology among primary care attenders. British Journal of Psychiatry 163, 37-44.

Woodruff R.S. \& Causey B.D. (1976). Computerized method for approximating the variance of a complicated estimate. Journal of the American Statistical Association 71, 315-321.

World Health Organization (1990). Composite International Diagnostic Interview (CIDI, Version 1.0). WHO: Geneva.

World Health Organization. (1991). Mental and behavioral disorders (including disorders of psychological development). In International Classification of Diseases. 10th Revision. Chap. 5 Diagnostic Criteria for Research, Draft for Field Trials. WHO: Geneva. 